\title{
Perspectives on the impact of stigma in leprosy: strategies to improve access to health care
}

This article was published in the following Dove Press journal:

Research and Reports in Tropical Medicine

18 September 2015

Number of times this article has been viewed

\section{Pamidipani SS Sundar Rao \\ LEPRA India, Secunderabad, India}

Correspondence: Pamidipani SS

Sundar Rao

LEPRA India, Plot No. 17, Krishnapuri

Colony, West Marredpally, Secunderabad,

Telengana 500026, India.

Tel +9l 8028445321

Email sundarraopss@rocketmail.com

\begin{abstract}
Throughout its history, leprosy has been much feared and misunderstood. Today, we have the best knowledge, expertise, therapies, and surgical and physiotherapeutic skills to virtually cure and eradicate the disease, but the continuing high levels of stigma pose insurmountable obstacles in our efforts to remove the scourges of leprosy. In this review, the medical, social, and political aspects related to the impact of stigma on leprosy are elaborated, and strategies for providing access to equitable and effective care are described. Leprosy is a biosocial disease, and experience has shown that both the medical and social dimensions must be aggressively confronted. Stigma in leprosy is based on religious, sociocultural, psychological, and demographic experience over centuries of human existence. Therefore, any attempt to eradicate or reduce stigma will require strong multifaceted approaches that will permeate psychological, social, and mental layers of the human mind and result in necessary health-seeking behaviors. What then is needed is a social multidrug therapy similar to the medical multidrug therapy, where there would be one arm for curing the medical problems of leprosy, a second arm focusing on empowering the people, especially affected persons, through appropriate education, awareness, especially for early detection and treatment, encouraging positive attitudes and perceptions, and a third arm for advocacy, attacking derogatory and discriminatory laws, enabling opportunities for persons with leprosy disabilities to be profitably employed, and providing necessary rehabilitation facilities. Health can never be adequately protected by health services without the active understanding and involvement of communities whose health is at stake. The review cautions that without a social multidisciplinary approach using communitybased participatory techniques, we cannot provide access to effective and acceptable health care to leprosy-affected persons.
\end{abstract}

Keywords: leprosy, stigma, social, MDT, health access

\section{Background}

The global registered number of leprosy cases during the first quarter of 2014 was 180,618, while new-case detections during the year were $215,656 .{ }^{1}$ The World Health Organization (WHO) also states that over 14 million leprosy patients have been "cured" by multidrug therapy (MDT) over the past 20 years. ${ }^{2}$ The reduction from an estimated 5.2 million cases of leprosy in 1985 to fewer than 200,000 in 2014 is astounding, considering the fact that during much of the 5,000 years leprosy has been around, it was a dreaded disease and written off as incurable, A brief chronology of major breakthroughs and approaches to control and eradication is summarized in Table 1.

In 1895, Hansen and Looft, who discovered the causative organism of leprosy, stated, "... there is hardly anything on earth or between it and heaven, which has not 
Table I Significant milestones in the control of leprosy

\begin{tabular}{lll}
\hline Event & Year & Reference(s) \\
\hline $\begin{array}{l}\text { Identification and description } \\
\text { of leprosy in Egypt }\end{array}$ & $1550 \mathrm{BC}$ & 4 \\
$\begin{array}{l}\text { Identification and description } \\
\text { of leprosy in India }\end{array}$ & $650 \mathrm{BC}$ & 9,78 \\
$\begin{array}{l}\text { Discovery of causative organism, } \\
\text { Mycobacterium leprae }\end{array}$ & 1895 & 3 \\
$\begin{array}{l}\text { Description of microbiology, } \\
\text { pathology, neurology }\end{array}$ & $1950-1970$ & 79,80 \\
$\begin{array}{l}\text { Discovery of first antileprosy } \\
\text { drug, dapsone (DDS) }\end{array}$ & $1940 \mathrm{~s}$ & 81 \\
$\begin{array}{l}\text { Development of reconstructive } \\
\text { surgery for deformities }\end{array}$ & $1950 \mathrm{~s}$ & 6 \\
$\begin{array}{l}\text { Mouse footpad cultivation of M. leprae } \\
\text { Development of multidrug therapy } \\
\text { World Health Organization } \\
\text { call for elimination of leprosy }\end{array}$ & $1960 \mathrm{~s}$ & 82 \\
\hline
\end{tabular}

been regarded as the cause of leprosy; and this is but natural, since the less one knows, the more actively does his imagination work". ${ }^{3}$ In Europe during the Middle Ages, leprosy sufferers had to wear special clothing, ring bells to warn others they were close, and even walk on a particular side of the road, depending on the direction of the wind. ${ }^{4}$ Today, we have the best knowledge, expertise, therapies, and surgical and physiotherapeutic skills to virtually cure and eradicate the disease. ${ }^{5}$ However, the continuing high levels of stigma and sociopsychological resistance to accept the truth act as the chief stumbling block. In this review, the perspectives related to the impact of stigma on leprosy are elaborated and strategies for providing access to equitable and effective care are described, based mainly from experiences in India, Nepal, the People's Republic of China and one or two other countries.

\section{Medical aspects of leprosy}

Despite its long history and various discoveries, much of the basic epidemiology of leprosy in terms of reservoirs, portal of entry, and exit of Mycobacterium leprae, the mode of transmission and the incubation period are still not clear. ${ }^{5}$ So far, attempts to culture the bacillus have failed, and this is one of the major challenges in developing effective methods of prevention and cure.

The early symptoms of leprosy are often painless hypopigmented anesthetic patches on the skin or painless small nodules on the earlobes or skin. ${ }^{6}$ Leprosy is thus considered a skin disease and referred to dermatologists. Left untreated, leprosy becomes progressively destructive, causing irreversible damage to the skin, nerves, limbs, and eyes. This causes deformities and ulcers due to the anesthesia that accompanies the invasion in the skin. Since the bacteria were not killed with effective drugs till the use of dapsone in the late 1940s and MDT in the 1980s, the affected person gradually developed primary deformities, resulting in secondary ulceration and damage to the limbs and eyes, which incapacitates and renders the person gradually incapable of carrying out essential daily activities.

Contrary to popular belief, leprosy does not cause body parts to fall off on their own accord, but rather they get eroded and traumatized, resulting in serious clinical conditions, including septicemia and gangrene, requiring amputations. Therefore, leprosy is a disease considered incurable, highly deforming, and leading to destitution and eventual death due to neglect and starvation. Due to stigma and several misconceptions, often there is considerable delay before diagnosis, and only after visible disabilities occur. But for these complications, which lead to irreversible nerve damage and consequent deformities, leprosy would have been a simple disease. ${ }^{7}$

\section{Psychosocial misconceptions of leprosy}

Stigma in leprosy is all-pervasive, ostracizing not just the individual but the family as well. ${ }^{8}$ Several classical Hindu scriptures, especially the Manu Smriti, clearly state that if there is leprosy in the family, one should not have any matrimonial alliances with such. ${ }^{9,10}$ There are several references in the Bible that leprosy is caused by divine intervention or as a punishment (Numbers 12:10, Deuteronomy 24:8, 2 Kings 5:27, 2 Chronicles 26:21, Matthew 8:2-3, Mark 1:40-42, Luke 5:12-13). ${ }^{11}$ This belief persists even after demonstration of the causative organism, by Hansen and Looft over a century ago. Many social restrictions stem from this notion, even when a person presents no visible disabilities, and sadly even when a patient is released from treatment after successful MDT or reconstructive surgery. ${ }^{12}$ Current medical and surgical therapies kill the bacteria and restore functional capacities, but cannot reverse the nerve damage causing anesthesia, which is responsible for many of the secondary disabilities. ${ }^{6}$ The education and provision of microcellular rubber footwear, although helpful, merely highlight the individual as leprosy-affected..$^{10}$ Further, wearing footwear itself may not be cultural acceptable, especially inside the house or temple. ${ }^{13}$ Therefore, current imperfections and inadequacy of medical models themselves lead to further stigma. ${ }^{13}$ Health professionals who hail from the same environment are themselves prejudiced, and have the same mind-set of leprosy being an incurable and 
undesirable disease. ${ }^{10,14}$ Unless there are stronger efforts for reorienting health professionals and leprosy workers, they are liable indirectly to infuse negative perceptions of the disease and support local theories. ${ }^{13}$

The second common misconception in leprosy is that it is a disabling disease, even after treatment, and that the patient progressively becomes more and more deformed and mutilated till he becomes helpless and destitute. ${ }^{13}$ The continuation of lepra reactions and chronic plantar ulcers despite successful MDT adds strength to this belief. Unless there are significant medical advances and breakthroughs in solving these problems, stigma against leprosy as an incurable disease will prevail. ${ }^{5}$

Thirdly, leprosy is considered by many to be hereditary, and transmission from parents to children is inevitable, although not visible in a given time. ${ }^{15,16}$ Lastly, one cannot diagnose infection or subclinical leprosy, and when some cardinal sign and symptoms occur, they may mimic other dermatological conditions or may even disappear, thus giving low credence to reporting leprosy in its early stages. ${ }^{6}$

Although leprosy occurs sometimes in well-to-do families, it is considered mostly as a disease of poverty and associated with those living in poor hygienic environments or working in menial jobs or close to soil. ${ }^{17,18}$ Often, education per se does not remove the inbuilt belief that leprosy is a punishment for past sins in earlier generations. ${ }^{19}$ The insults and injustices meted out through various discriminatory laws, eg, in India, are shown in Table $2 .^{20}$

Therefore, leprosy stigma is deeply rooted in religious, social, political, and cultural domains, and needs significant

Table 2 Discriminatory laws against people affected by leprosy in India

\begin{tabular}{ll}
\hline Law & Year passed \\
\hline Indian Divorce Act & 1869 \\
Indian Christian Marriage Act & 1872 \\
Bombay Municipal Corporation Act & 1888 \\
Dissolution of Muslim Marriage Act & 1939 \\
Industrial Disputes Act & 1947 \\
Hindu Special Marriage Act: section 27(I)(g) & 1954 \\
Hindu Marriage Act: section I3(IV) & 1955 \\
Hindu Adoption and Maintenance Act (section I8) & 1956 \\
Prevention of Begging Act & 1959 \\
Maharashtra State Road Transport Corporation Act & 1980 \\
Life Insurance Corporation Act, amendment & 1987 \\
Motor Vehicle Act & 1988 \\
Indian Railways Act (section 56) & 1989 \\
Rehabilitation Council of India Act & 1992 \\
Persons with Disability Act & 1995 \\
Juvenile Justice and Care and Protection Act & 2000 \\
(sections 48, 58) & \\
\hline
\end{tabular}

developments not only in the current medical knowledge or technology to make cure a reality but in our radical strategies in community-based approaches. ${ }^{5}$

\section{Perspectives on impact of stigma on leprosy}

In 1963, Goffman defined stigma as "spoiled identity", ${ }^{21}$ and classified individuals involved in the process of stigma into three categories: 1) "stigmatized" are those who are ostracized, devalued, rejected, scorned, or shunned; they experience discrimination, insults, and attacks, and are even murdered; 2) "normals" are those who do not bear the stigma; and 3 ) "wise" are those among the normals who are accepted by the stigmatized as "wise" to their condition. In 1998, Scambler ${ }^{22,23}$ distinguished between perceived (felt) stigma and enacted (behavior) stigma, where perceived stigma is the psychological distress and attitudes of the affected individual, who seeks to hide the disease or isolate himself or herself from normal social interactions. On the other hand, enacted stigma restricts the participation of the affected persons in routine activities by family, colleagues, and generally society. Weiss et $\mathrm{al}^{24}$ defined stigma in 2006 as a social process or related personal experience characterized by exclusion, rejection, blame, or devaluation that results from experience or reasonable anticipation of an adverse social judgment about a person or group identified with a particular problem.

The understanding of causation in terms of microbes is a relatively new idea in the minds of many populations..$^{25}$ Environmental factors, such as miasma, divine retribution for past sins and disobedience to Gods, concepts of hot and cold foods, elimination diets, talismans, and holy waters have all played their part in the preventive and curative aspects of devastating illnesses, such as smallpox, tuberculosis, cancers, and mental illnesses. ${ }^{26}$ Integration of leprosy services into the general health system has the potential to encourage leprosy patients to seek help in diagnosis and treatment, especially in the early stages. However, analyses of new-case detections at primary health centers in India show that this has not happened. ${ }^{27}$ Further, health-seeking habits show that leprosy patients still prefer local healers to diagnose, counsel, and treat. ${ }^{28}$ Therefore, evidence shows the limitation of powerful drugs, such as MDT and corticosteroids, in effective preventive and curative measures in the stigmatized environment. ${ }^{29,30}$ A recent study showed that despite massive expenditures on information, education, and communication (IEC) activities by the government, significant numbers of public in India's largest state, Uttar Pradesh, are ignorant of integration of leprosy services. ${ }^{31}$ 
Given the long history of stigma in leprosy, any attempt to eradicate or reduce stigma will require strong multifaceted approaches that will permeate psychological and social layers of the human mind and result in necessary health-seeking behaviors. ${ }^{32}$ The present educational interventions under the label of IEC have proved to be woefully inadequate, and thus require revolutionary changes. ${ }^{33,34}$ There is therefore an urgent need to totally modify the current IEC strategies to a more sophisticated knowledge-translation protocol, as described by Kuipers et al. ${ }^{35}$ Essentially, the conceptual protocol describes in broad terms a five-phase psychosocial and service-related research program to overcome stigma and negative attitudes for prevention of delay in diagnosis, improvement of adherence to MDT, the rollout of chemoprophylaxis, and increased participation in community-based rehabilitation. ${ }^{35}$ Strong advocacy and great public commitment are essential ingredients of a new strategy, which will use biosocial models rather than separate medical or social models.

Of late, it has become fashionable to combine stigma in leprosy with that in other diseases, such as HIV, mental illness, or tuberculosis, and generate common platforms for its eradication. ${ }^{36}$ The origins and manifestations as well as beliefs on stigma vary for each of the stigmatized diseases; success in achieving reduction or elimination of stigma must be tailored and customized to specific diseases. ${ }^{25}$ Stigma and discrimination with regard to any disease are undesirable, and sharing of experiences across several health events might have some benefits. However, the solutions might become diluted or ineffective under a common banner. Not only will the focus be blurred but the common approach might be construed as unrealistic and unacceptable for practice. ${ }^{19}$ Keeping a broad perspective, one should aim for specific strategies, due to the uniqueness of leprosy-related stigma compared to other health-related stigma, noting down similarities and differences. ${ }^{36}$

One should carefully distinguish perceived and enacted stigma, and efforts made to combat both. ${ }^{37}$ While many laws address injustice, discrimination, and social restrictions, one should not ignore the heavy anxieties and powerful perceptions of the affected person or the family, especially women, which act as a strong barrier to proper health-seeking behaviors. ${ }^{38,39}$ Perceptions of leprosy can be very negative in a highly educated person and even medical professionals. Therefore, perceived stigma needs a different strategy to be reduced or eradicated..$^{29,40}$

Stigma is not a fixed entity, and can change over time or in different environments. ${ }^{33}$ It is dynamic, and the solutions must take advantage of local strengths and opportunities.
Insights have been gained from data collected over a year from frontline leprosy workers in India. Unfortunately, health professionals themselves become initiators of stigma, due to their mind-sets or carelessness. ${ }^{13-15}$

\section{Strategies to improve access to health care}

Based on the assumption that the health service provider knew everything that needed to be done for leprosy at a given point of time, and that the community was only a passive recipient of services, the role of the individual, the family, and the community in leprosy control and management was not given due importance over the past few decades. ${ }^{41,42}$ In much of the recent literature, leprosy stigma is interpreted as the chief stumbling block for control and eradication of leprosy, overlooking the cultural and historical basis of such stigma and other root causes of stigma that could be context-specific. ${ }^{43}$ It is high time that a more logical and effective system of leprosy-stigma reduction be evolved, taking into account the various perspectives - cultural, medical, historical, socioeconomic, and demographic - that may be specific to each society. ${ }^{44,45}$ A conceptual framework for such a strategy is described in Figure 1.

This implies the development of "social" MDT similar to medical MDT, where multiple drugs are used to kill the bacteria, control the inflammatory responses, and have a static drug, such as dapsone. ${ }^{46,47}$ Likewise, social MDT would have one arm for curing the medical problems of leprosy, providing accessible and affordable MDT and steroids, for reactions and nerve-function impairments, and efficient reconstructive surgery and physiotherapy, ${ }^{48,49}$ a second arm focusing on empowering the people, especially the affected persons, through appropriate education, awareness, especially

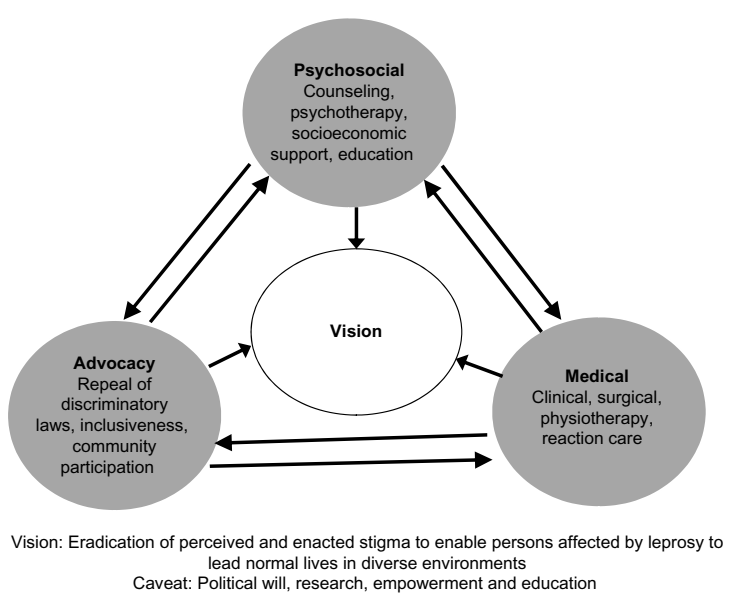

Figure I Conceptual framework. 
for early detection and treatment, and encouraging positive attitudes and perceptions, ${ }^{50-52}$ and a third arm exclusively for advocacy, attacking derogatory and discriminatory laws, and enabling opportunities for persons with leprosy disabilities to be profitably employed and providing necessary rehabilitation facilities. ${ }^{53,54}$ Each of these arms is further elaborated in the following sections for improving access to health care and development.

\section{Medical arm}

Early detection and contact tracing form the sheet anchor of prevention strategies in the interruption of leprosy transmission. ${ }^{48}$ After the availability of MDT and the WHO call for global elimination of leprosy, the vertical system was abandoned and leprosy services integrated into general health services, starting at primary health centers. All medical officers and allied health staff were trained to detect and treat leprosy. ${ }^{49}$ Integration of leprosy services meant that people had free access to government health services, including free MDT and diagnoses of any complications. The integrated service also brought in a large number of female professionals who were trained to examine women and children more thoroughly, which was lacking in the earlier vertical system, which had predominantly only male workers. ${ }^{27}$ Integration of leprosy was especially a boon in rural areas for early detection and prompt treatment. The main drawback was the lack of consistent training of the new medical officers who replaced those who moved on for higher studies or elsewhere. The vast army of other general health and development personnel, such as auxiliary nurses, physiotherapists, pharmacists, and nutrition workers, need to be constantly trained and motivated to search for early cases and direct them to start MDT. Gradually, primary health centers should be able to diagnose reactions and either provide corticosteroids or refer patients to specialist care. They should also help actively in ulcer care, especially of the feet, providing protective footwear, counseling, and training in self-care. No doubt there are some deficiencies in skilled manpower, MDT, or necessary drugs, but there are serious and sincere attempts to solve these problems. ${ }^{49}$ Some leprosy patients who suffer from adverse consequences, such as neuritis or reactions that cannot be handled at the primary health center level, can be referred promptly to a higher level, such as a district hospital or other specialist center for proper diagnosis and treatment. ${ }^{55}$ These patients are then followed up at the local level. These referral services are an essential part of a national health system, but are often weak and dysfunctional in some instances. The major challenge in early case detection, especially among contacts of index leprosy cases, is the prevailing ignorance and stigma and the hope that it may not be leprosy after all. In this age of explosive information technology and the use of affordable hardware and software, use of mobile phones, telemedicine and tele-education seem attractive strategies. An overview and future directions for research and implementation were discussed by Nelson et al. ${ }^{56}$ The application of such strategies provides improved access to expert health care for leprosy patients scattered in low-accessibility areas. Location of possible suspects, screening, and starting MDT are critical first steps in leprosy eradication. Social marketing and close interactions with the communities provide the means for implementing these potentially effective measures for early case detection, as well as early detection of complications that are best managed through the latest medical technologies. ${ }^{34,57}$

In summary, the medical arm provides necessary effective leprosy care supported by necessary laboratory services providing diagnostic and therapeutic services at various levels that are affordable, acceptable, and accessible to all leprosy patients who need them. The problem arises when patients do not seek appropriate care early at the right place, due to many psychosocial factors, and hence the need for the critical second arm, which is discussed in the next section. ${ }^{45,52,58}$

\section{Psychosocial arm}

Even the best medical care becomes ineffective if the affected persons and their families do not cooperate by reporting early, provide correct history, and adhere to prescribed treatment. In the case of leprosy, there is considerable delay in reporting, incomplete or inaccurate history, and much defaulting. There are many reasons that must be compassionately inquired into and overcome. ${ }^{59-62}$ Fear of leprosy, guilt, stigma, and discrimination associated with the disease in the community and unfounded prejudices regarding leprosy force a person to hide the disease and contribute to delays in seeking treatment, and thus promote transmission of the disease..$^{15,41}$ People still believe that leprosy inevitably results in gross deformities, which could have been otherwise prevented by early diagnosis and treatment with MDT. ${ }^{12,42}$ Ideally, the desirable course of an affected person should be that he/she seeks medical attention, accepts diagnosis, adheres to medical advice, starts treatment, continues treatment, discusses problems, pursues an independent life, practices self care, and approaches health centers for follow-up. On the other hand, the most undesirable course could be that the affected person would hide, run away, ignore, deny, seek local remedies, refuse medical advice and treatment, seek other medications, stop treatment, ignore 
medical advice, ignore the problem, plead for continuation of treatment, approach other centers, and get isolated. Eventually, the person becomes a burden on society. ${ }^{13,50,63}$

As in the provision of medical care, the psychological and psychosocial problems arising due to perceived and enacted stigma must be addressed effectively at every level. ${ }^{52}$ The primary level is probably the most important when the person affected first suspects the disease and becomes worried if the disease becomes public knowledge and results in tragic consequences. ${ }^{33,43}$ The negative reaction of their family, friends, and community aggravates their declining morale and overall psychological state. In many patients, suicidal thoughts come after the diagnosis of leprosy. ${ }^{63}$ Many patients have committed suicide in hospitals and at home, as they had undergone extreme psychosocial stress and depression. The social environment around the patient is responsible to a large extent for damage to the patient's psyche. The patient needs psychological support and counseling as soon as the diagnosis of leprosy is made. ${ }^{46}$

For a married woman, it is a question of dissolution of her marriage, ${ }^{60}$ and for an earning person, it could be loss of the job and wages ${ }^{64,65}$ if leprosy progresses. Proper counseling and positive health-seeking habits are critical, and psychosocial support by the family to report and start treatment will ensure total cure. Young leprosy-affected children have difficulty in getting admission into schools. Employers do not like to employ leprosy-affected persons. Leprosy-affected persons also have difficulties in accessing public services, such as transport and accommodation in hotels. Marriage in a family where a leprosy-affected person lives is a problem. ${ }^{9}$

It is here that acceptable and accessible medical care complements the counseling and coping with the problem. As the disease progresses without proper treatment and when disabilities occur, both primary and secondary medical care are available only if the proper education and counseling are given. Psychosocial problems are inherent in many chronic and disabling ailments, but the stigma in leprosy imposes an undue dilemma in seeking the best possible course of treatment. Often, only the family can give solid support, especially when children and breadwinners are affected. ${ }^{52,66}$ Occupational therapists have a special role in reeducation and reorientation to patients who cannot continue their earlier jobs due to anesthesia or deformities ${ }^{67}$ The best medical and surgical care still needs strong psychosocial support. Enacted stigma is primarily strong in social participation restrictions, which interfere with the role and dignity of the affected person. ${ }^{25,43,68}$ If the affected person loses their job, resulting in economic hardship, the ego suffers further. ${ }^{65}$
There is still a need for special counseling, inclusive care, job opportunities, and restoration of a person's dignity, resulting in maintaining quality of life.$^{51}$ Competent career counselors and guidance in making the right choices for independence are essential to prevent the downward slide of the deformed patient. As far as possible, dehabilitation must be prevented through family counseling and support. Socioeconomic problems can arise even if the affected person has no disabilities and has successfully completed the required course of MDT. Goffman's label of "spoiled" identity becomes an indelible stain or tattoo of someone diagnosed with leprosy, and can only be removed through intense education, demonstration, and positive performances. ${ }^{33,42,45}$ Despite the best medical and psychological care, there is still a need for a proper environment to be created, and this is detailed in the third arm of the multifaceted strategy.

\section{Advocacy and reengineering societal perspectives}

Stigma in leprosy has developed over centuries of ignorance, superstition, misconception, and experience. In this process, religion and sacred writings have played no small part, ,,11,68 and have instigated laws and rites to protect society from socalled lepers, an undignified term that is still used in common parlance as an undesirable element and burden in the society. Religious proscriptions have led to civil discriminatory laws, many of them considered beneficial to society. ${ }^{8}$ Many countries have repealed archaic and often unjust laws against persons affected by leprosy, and have even taken positive steps for inclusiveness. ${ }^{69}$ It is rather unfortunate that India, with the largest number of leprosy cases and which has generated the greatest discoveries in the diagnosis and treatment of leprosy, continues to debate on the repeal of discriminatory laws and soft-pedaling on their implementation.

To eradicate the stigma in leprosy, we now have this stupendous task of reeducation and reorientation to reengineer the societal framework in the light of current knowledge on leprosy. The availability of MDT and the best medical therapies has solved much of the physical ravages of leprosy. ${ }^{47,49}$ The best of psychological and psychiatric care have contributed immensely in alleviating the fear and anxieties about the disease, providing scientific knowledge on dispelling wrong notions on the notions of leprosy consequences and cutting the link between leprosy and deformity. ${ }^{46}$ These are no small steps in making effective health care accessible to all those affected by leprosy. However, there is the last battle to be won against societal mind-sets based on ingrained and embedded religious and other teachings. This battle can only 
be won with strong political will and intensive communityparticipatory approaches to repeal all discriminatory laws against leprosy-affected persons, ${ }^{42,70}$ so as to generate a more positive, just, inclusive, and favorable environment where there is no stigma against leprosy.

Community-based action research is a relatively new initiative $^{71,72}$ where heath service professionals and sociologists along with community leaders and local experts design and implement an intervention program and themselves evaluate the outcomes. It is recognized as a critical strategy in addressing health unfairness among socially disadvantaged and marginalized communities. ${ }^{73,74}$ From the beginning of a community-based participatory-approach project, community members are invited to share decisionmaking authority with all other partners involved. The basic principles inherent in a community-based participatory approach include recognizing the community as a unit of identity, building on collective strengths and shared resources, facilitating partnership and capacity building throughout the process, spreading relevant information, data, and other findings to all participants, involving a long-term process and commitment, and seeking a balance between research and action. ${ }^{75}$ Health can never be adequately protected by health services without the active understanding and involvement of communities whose health is at stake. ${ }^{76}$

In a thought-provoking book on community-based participatory research, Israel et al laid the principles and practice systematically and provided many examples of successful projects. ${ }^{71}$ In a landmark work of the Leprosy Mission Trust India, initiated in 2005 for nearly 7 years, Raju et al provided case studies in three states of India of eliminating leprosy stigma through truly community-based participatory approaches..$^{77}$ In partnership and consultation with community leaders, a stigma-reduction organizing committee was formed in each main village as a first step. Through these, a number of activities were systematically planned, several involving persons affected by leprosy. These included rallies, mass meetings, wall painting of slogans, dance dramas, video shows, common meals, and health camps, all aimed at knowledge enhancement and attitudinal changes to eliminate stigma. This project, which was planned as a randomized field trial with intervention and control villages in the three states, has shown encouraging results even in the short term. ${ }^{77}$

The community health action model includes merging the community-development process with a compatible community-assessment, planning, implementation, and evaluation framework. Using this model, the community takes ownership, gives direction, and assumes responsibility for its activities and the resulting outcomes through public participation; community members come together and interact as a collective unit. ${ }^{42,76,77}$

Advocacy and replacement of outdated acts/laws are great challenges in a democratic and bureaucratic government, and could be accelerated if scientists working in the field of leprosy can clarify without any credibility gap some further doubts and remove confusion/misconceptions about leprosy from the minds of people at large, including the medical fraternity and lawmakers. Gray areas of our knowledge could be genetic susceptibility, incubation period, curability, extra- and nonhuman reservoirs for M. leprae, and whether a cured leprosy patient can donate blood. However, we have more than adequate knowledge now to act. Social justice cannot be achieved by following the letter of the law, but only by proactive actions. Administrative and policy changes need to ensure the human rights of the patients. ${ }^{45,54}$

\section{Concluding remarks}

This review has covered an extensive period where scientists and anthropologists have contributed significantly in unraveling the mysteries of an ancient disease. Both governments and nongovernmental organizations, as well as medical and nonmedical professionals, have helped usher greater hope that eradication of leprosy is near. The review has also strongly cautioned that without some radical changes in the implementation of WHO operational guidelines using community-based participatory techniques, we have only a poor chance of beating the challenge for providing access to effective and acceptable health care to leprosy-affected persons.

So far, leprosy programs have been very top-down bureaucratic undertakings, spending enormous amounts of money but with little participation by the community. Today, such approaches are in fact unethical and irrational, when the problem of leprosy is for the people affected by leprosy and the solution must arise from the people and be owned by the community. A Chinese proverb states: "Go to the people, live among them, learn from them, and when then job is done, the people will say, we did it ourselves". Unfortunately, all these nuggets of wisdom are well known by all the top administrators and professionals, but they all pay only lip service to community-based programs. Therefore, failure is built-in. It is time we change, and change drastically. 


\section{Disclosure}

The author reports no conflicts of interest in this work.

\section{References}

1. [No authors listed]. Global leprosy update, 2013;reducing the burden of leprosy. Wkly Epidemiol Rec. 2014;89:389-400.

2. World Health Organization. Leprosy: fact sheet 101. 2015. Available from: http://www.who.int/mediacentre/factsheets/fs101/en. Accessed July 3, 2015.

3. Hansen GA, Looft C. Leprosy in Its Clinical and Pathological Aspects. London: John Wright; 1895.

4. Stanford University. History of leprosy. 2005. Available from: http:// web.stanford.edu/group/parasites/ParaSites2005/Leprosy/history/htm. Accessed.

5. Sundar Rao PS. Worldwide Elimination of Leprosy. Expert Rev Dermatol. 2012;7:513-520.

6. Bryceson A, Roy EP. Leprosy. 3rd ed. London: Churchill Livingstone; 1990.

7. Lockwood DN, Suneetha S. Leprosy: too complex a disease for simple elimination paradigm. Bull World Health Organ. 2005;83:230-235.

8. Frist TF. Stigma and the societal response to leprosy: experience of the last half-century. Indian J Lepr. 2000;72:1-3.

9. Fordham University. Indian history sourcebook: The Laws of Manu, c. 1500 BCE, translated by G. Buhler. 1998. Available from: http://www. fordham.edu/halsall/india/manu-full.html. Accessed July 3, 2015.

10. Dongre VV. Anubhav - Experiences in Health and Community Development: Leprosy Elimination - Crossing the Oceans of Stigma. New Delhi: Vhai; 2003.

11. [No authors listed]. Holy Bible: New International Version. Grand Rapids (MI): Zondervan; 2000.

12. Mutatkar RK. Society and Leprosy. Pune, India: Shubada-Saraswat; 1979.

13. Srinivasan H. Rehabilitation of leprosy-affected persons - some misconceptions. Health Adm. 2006;18:84-91.

14. Dodor EA, Kelly S, Neal K. Health professionals as stigmatisers of tuberculosis: insights from community members and patients with TB in an urban district bin Ghana. Psychol Health Med. 2009;14:301-310.

15. Barkataki P, Kumar S, Rao PS. Knowledge of and attitudes to leprosy among patients and community members: a comparative study in Uttar Pradesh, India. Lepr Rev. 2006;77:62-68.

16. Bainson KA, van den Borne B. Dimensions and process of stigmatization in leprosy. Lepr Rev. 1998;69:341-350.

17. Bonney JJ. Responding to the socio-economic implications of leprosy. Lepr Rev. 2011;82:98-102.

18. Navon L. Beggars, metaphors and stigma: a missing link in the social history of leprosy. Soc Hist Med. 1998;11:89-105.

19. Sinha AK, Banerjee BG, Singh S. Leprosy and its socio-cultural perception in Indian religions and ancient texts. Indian J Lepr. 2010;82: $1-21$.

20. HT correspondent. Some laws discriminate against people with leprosy: law panel. 2015. Available from: http://www.hindustantimes.com/indianews/some-laws-discriminate-against-people-with-leprosy-law-panel/ article1-1334919.aspx. Accessed July 3, 2015.

21. Goffman E. Stigma: Notes on the Management of Spoiled Identity. London: Penguin Group; 1963.

22. Scambler G. Stigma and disease: changing paradigms. Lancet. 1998;352: 1054-1055.

23. Scambler G. Re-framing stigma: felt and enacted stigma and challenges to the sociology of chronic and disabling conditions. Soc Theory Health. 2004;2:29-46.

24. Weiss MG, Ramakrishna J, Somma D. Health related stigma: rethinking concepts and interventions. Psychol Health Med. 2006;11:277-287.

25. Staples J. Interrogating leprosy 'stigma': why qualitative insights are vital. Lepr Rev. 2011;82:91-97.
26. Kaur H, Anjali G. People's perception of leprosy - a study in Delhi. Indian J Lepr. 2003;75:43-46.

27. Pandey A, Rathod H. Integration of leprosy in general health system vis-à-vis leprosy endemicity, health situation and socioeconomic development: observations from Chhattisgarh and Kerala. Lepr Rev. 2010;81:121-128.

28. Samraj A, Kaki S, Rao PS. Help-seeking habits of untreated leprosy patients reporting to a referral hospital in Uttar Pradesh, India. Indian J Lepr. 2012;83:123-129.

29. Heijnders ML. The dynamics of stigma in leprosy. Int $J$ Lepr Other Mycobact Dis. 2004;72:437-447.

30. Sinha A, Kushwaha AS, Kotwal A, Sanghi S, Verma AK. Stigma in leprosy: miles to go. Indian J Lepr. 2010;82:137-145.

31. Verma C, Rao PS, Raju MS. Public awareness on integration of leprosy services at primary health centres in Uttar Pradesh, India. Indian J Lepr. 2011;83:95-100.

32. Link BG, Phelan JC. Conceptualizing stigma. Annu Rev Sociol. 2001;27:363-385.

33. Kazeem O, Adegun T. Leprosy stigma: ironing out the creases. Lepr Rev. 2011;82:103-108.

34. Wong ML. Designing programmes to address stigma in leprosy: issues and challenges. Asia Pac Disabil Rehabil J. 2004;15:3-12.

35. Kuipers P, Rao PS, Raju MS, John AS, Sabuni LP. A conceptual protocol for translational research in the complex reality of leprosy. Lepr Rev. 2013;84:166-174.

36. Rao PS. Study on differences and similarities in the concept and origin of leprosy stigma in relation to other health-related stigma. Indian $J$ Lepr. 2010;82:117-121.

37. Rao PS, Raju MS, Barkataki A, Nanda NK, Kumar S. Extent and correlates of leprosy stigma in rural India. Indian J Lepr. 2008;80: 167-174.

38. John AS, Kumar DV, Rao PS. Patients' perceptions of reconstructive surgery in leprosy. Lepr Rev. 2005;76:48-51.

39. Cakiner T, Yüksel A, Soydan M, Saylan T, Bahçeci E. Women and leprosy in Turkey. Indian J Lepr. 1993;65:59-67.

40. Hyland JE. Sociocultural Study of Leprosy in Nepal: Patient Illness Career Patterns and Health Education [doctoral thesis]. Hobart, Australia: University of Tasmania; 1993.

41. Heijnders ML. An exploration of views of people with leprosy in Nepal concerning quality of leprosy services and their impact on adherence behavior. Lepr Rev. 2004;75:338-347.

42. Murugesan N. Reaching to the communities - advocacy, education, community participation and impact on leprosy programme. Health Adm. 2006;18:73-77.

43. Rafferty J. Curing the stigma of leprosy. Lepr Rev. 2005;76:119-126.

44. Nsagha DS, Bissek AZ, Nsagha SM, et al. Social stigma as an epidemiological determinant for leprosy elimination in Cameroon. J Public Health Africa. 2001;2:38-44.

45. Sasakawa Y. Global appeal to end stigma and discrimination against people affected by leprosy. Health Adm. 2006;18:91.

46. Government of India. Social Stigma in Leprosy: Report and Recommendations of the National Workshop on Stigma and Leprosy. New Delhi: GOI; 2011.

47. World Health Organization. WHO Expert Committee on Leprosy: Eighth Report. Geneva: WHO; 2012

48. Smith CS, Aerts A. Role of contact tracing and prevention strategies in the interruption of leprosy transmission. Lepr Rev. 2014;85:2-17.

49. World Health Organization. Enhanced Global Strategy for Further Reducing the Disease Burden Due to Leprosy (2011-2015): Operational Guidelines. New Delhi: WHO Regional Office for South-East Asia; 2009.

50. Cross H, Choudhary R. STEP: an intervention to address the issue of stigma related to leprosy in southern Nepal. Lepr Rev. 2005;76: $316-324$.

51. Chen S, Chu T, Wang Q. Qualitative assessment of social, economic and medical needs for ex-leprosy patients living in leprosy villages in Shandong Province, the People's Republic of China. Lepr Rev. 2005; 76: $335-347$. 
52. Gopal PK. Psychosocial aspects. In: Kar HK, Kumar B, editors. IAL Textbook of Leprosy. New Delhi: Jaypee Brothers Medical Publishers; 2010:559-564.

53. Thomas MV, Rao PS. Unmet needs of rehabilitation in leprosy services. Lepr Rev. 2000;71:526-527.

54. Sundar Rao PS. Leprosy scenario beyond 2010. In: Kar HK, Kumar B, editors. IAL Textbook of Leprosy. New Delhi: Jaypee Brothers Medical Publishers; 2010:605-612.

55. Rao PS. Referral system: a vital link in the sustainability of leprosy services. Lepr Rev. 2010;81:292-298.

56. Nelson CA, Kovarik CL, Morssink CB. Tele-leprology: A literature review of applications of telemedicine and tele-education to leprosy. Lepr Rev. 2014;85:250-261.

57. Wong ML. Can social marketing be applied to leprosy programmes? Lepr Rev. 2002;73:308-318.

58. Manimozhi N. Health education, promotion and counselling. In: Kar HK, Kumar B, editors. IAL Textbook of Leprosy. New Delhi: Jaypee Brothers Medical Publishers; 2010:545-558.

59. Bekri W, Gebre S, Mengiste A, Saunderson PR, Zewge S. Delay in presentation and start of treatment in leprosy patients: a case-control study of disabled and non-disabled patients in three different settings in Ethiopia. Int J Lepr Other Mycobact Dis. 1998;66:1-9.

60. Try L. Gendered experiences: marriage and the stigma of leprosy. Asia Pac Disabil Rehabil J. 2006;17:55-72.

61. Rao PS. A study on non-adherence to MDT among leprosy patients. Indian J Lepr. 2008;80:149-154.

62. Chen XS, Li WZ, Jiang C, Ye GY. Leprosy in China: delay in the detection of cases. Ann Trop Med Parasitol. 2000;94:181-188.

63. Barrett R. Self-mortification and the stigma of leprosy in northern India. Med Anthropol Q. 2005;19:216-230.

64. Calcraft JH. The effects of the stigma of leprosy on the income generation of leprosy affected people in the Terai area of south east Nepal. Asia Pac Disabil Rehabil J. 2006;17:73-89.

65. Rao PS, Darlong F, Timothy M, Kumar S, Abraham S, Kurian R. Disability adjusted working life years (DAWLYs) of leprosy affected persons in India. Indian J Med Res. 2013;137:907-910.

66. Floyd-Richard M, Gurung S. Stigma reduction through group counselling of persons affected by leprosy - a pilot study. Lepr Rev. 2000;71: 499-504.

67. Shah A, Shah N. Deformities of face, hands and feet, and their management. In: Kar HK, Kumar B, editors. IAL Textbook of Leprosy. New Delhi: Jaypee Brothers Medical Publishers; 2010:424-446.
68. Morrison A. A woman with leprosy is in double jeopardy. Lepr Rev. 2000;71:128-143.

69. McCurry J. Japanese leprosy patients continue to fight social stigma. 2 years after landmark court ruling, incarcerated patients are still fearful of returning home. Lancet. 2004;363:544.

70. Minkler M, Garcia AP, Rubin V, Wallerstein N. Community-Based Participatory Research: A Strategy for Building Healthy Communities and Promoting Health Through Policy Change. Oakland (CA): School of Public Health, University of California, Berkeley; 2012.

71. Israel BA, Eng E, Schulz AJ, Parker EA (Eds). Methods for CommunityBased Participatory Research for Health. 2nd ed. Hoboken (NJ): John Wiley \& Sons; 2012.

72. Pollard N, Sakellariou D. Operationalizing community participation in community based rehabilitation: exploring the factors. Disabil Rehabil. 2008;30:62-70.

73. Nicolaidis C, Wahab S, Trimble J, et al. The Interconnections Project: development and evaluation of a community-based depression program for African American violence survivors. J Gen Intern Med. 2013;28: 530-538.

74. Karmaliani R, McFarlane J, Asad N, et al. Applying community-based participatory research methods to improve maternal and child health in Karachi, Pakistan. Nurs Outlook. 2009;57:204-209.

75. de Stigter DH, de Geus L, Heynders ML. Leprosy: between acceptance and segregation, community behaviour towards persons affected by leprosy in eastern Nepal. Lepr Rev. 2000;71:492-498.

76. Racher FE. The community health action model: health promotion by the community. 2007. Available from: http://www.brandonu.ca/rdi/ files/2011/03/CHA_ModeWorkingPaper.pdf. Accessed July 4, 2015.

77. Raju MS, Rao PS, Mutatkar RK. Eliminating Leprosy Stigma: A Manual for Community Action. New Delhi: SR Health Sciences Pvt Ltd; 2014.

78. Dharmendra S. Leprosy in ancient India. Int J Lepr. 1947;15:424-430.

79. Carter HV. Note on the Pathology of Leprosy. Maharashtra State Archives General Department. 1883;14494:7.

80. Rogers L. The treatment of leprosy. Ind Med Gaz. 1920:125-128.

81. Cochrane RG. A Practical Textbook of Leprosy. London: Oxford University Press; 1947.

82. Shepard CC. The experimental disease that follows the infections of human leprosy bacilli into the foot-pads of mice. J Exp Med. 1960;112: $445-454$.
Research and Reports in Tropical Medicine

\section{Publish your work in this journal}

Research and Reports in Tropical Medicine is an international, peerreviewed, open access journal publishing original research, case reports, editorials, reviews and commentaries on all areas of tropical medicine including: Diseases and medicine in tropical regions; Entomology; Epidemiology; Health economics issues; Infectious disease; Laboratory

\section{Dovepress}

science and new technology in tropical medicine; Parasitology; Public health medicine/health care policy in tropical regions; and Microbiology. The manuscript management system is completely online and includes a very quick and fair peer-review system. Visit http://www.dovepress. com/testimonials.php to read real quotes from published authors. 